\title{
O significado das aulas de Educação Física para adolescentes
}

\author{
Elio Oliveira Cruz \\ Geraldo Antônio Fiamenghi Junior \\ Pós-Graduação em Distúrbios do Desenvolvimento, CCBS da Universidade Presbiteriana \\ Mackenzie, São Paulo, SP, Brasil
}

\begin{abstract}
Resumo: A presente pesquisa é um estudo sobre o significado da atividade física para adolescentes e sua relação com os estados emocionais. Os participantes foram 100 alunos adolescentes de ambos os sexos, entre 13 e 15 anos, cursando a $8^{a}$ série de uma escola da rede SESI, na cidade de São Paulo, tendo como procedimento a aplicação de questionários, com perguntas objetivas sobre seus sentimentos e percepções em relação às aulas de Educação Física e seus estados emocionais. Os resultados mostraram a importância das aulas de Educação Física para o desenvolvimento das relações sócio-afetivas dos adolescentes. Além disso, observou-se a importância da atividade física para que os adolescentes tenham alternativas de lidar com as questões relacionadas ao corpo e às mudanças emocionais vivenciadas nesta idade. Finalmente, é fundamental que o profissional de Educação Física desenvolver valores éticos e morais seguros, para evitar a pressão de grupos sociais, principalmente aqueles ligados à mídia, que possam influenciar negativamente os adolescentes.
\end{abstract}

Palavras-chave: Adolescentes. Educação Física. Estados emocionais. Desenvolvimento social.

\section{The meaning of Physical Education classes for adolescents}

\begin{abstract}
This research aimed to study the meaning of physical activities for adolescents and its relation to emotional states. Participants were 100 13-to-15-year-old both sexes $8^{\text {th }}$ grade teenagers, from one of São Paulo's SESI school. The instrument was a questionnaire with objective questions about adolescents' feelings and perceptions on Physical Education classes and their emotional states. Results showed the importance of Physical Education classes for the development of adolescents socio-affective relations. Besides, the importance of Physical Education was acknowledged, as an alternative way of helping the adolescents to deal with questions related to their bodies as well as emotional changes due to their age. Finally, it is adamant that the Physical Education professional develops strong ethical and moral values, to avoid the pressure of social groups, especially those connected to media that may harmfully influence adolescents.
\end{abstract}

Key Words: Adolescence. Physical Education. Emotional states. Social development.

\section{Introdução}

Nas aulas de Educação Física, embora grande parte dos alunos sinta-se atraída pelas atividades desenvolvidas, outra parte não se motiva a realizá-las, a despeito das facilidades ou dificuldades técnicas. Quando questionados sobre esta atitude indiferente, os alunos demonstram que, em algum momento em sua vida escolar, nas aulas de Educação Física, foram expostos a um constrangimento, por colegas de turma, ou até por algum professor e esta atitude fez com que estes alunos ficassem inseguros em relação às aulas praticas e jogos. Muitos até gostariam de estar envolvidos e participando das aulas, porém, com medo ou vergonha de serem expostos novamente, preferem se afastar, tentando ficar 'invisíveis' durante as aulas de Educação Física, que exigem algum tipo de habilidade especifica, as quais eles acreditam não possuir. Por outro lado, existem também aqueles alunos que gostam e necessitam estar em evidência, quer por sua suposta habilidade, quer pela liderança e carisma que exercem sobre o grupo.

Fiamenghi (2001) afirma que conceituar emoção em Psicologia é bastante difícil e isso se deve ao fato de haver divergências quanto à definição de emoção e vai considerar emoções de forma ampla, "como reações, fisiológicas e psicológicas que exercem influência sobre a percepção, aprendizagem e desempenho" (p. 20).

Parece haver uma dificuldade das pessoas descreverem suas emoções através da verbalização e já que as emoções são vivenciadas no corpo, atividades físicas podem trazer benefícios aos aspectos emocionais do adolescente, pois, segundo Fiamenghi (2001) a 
emoção pode ser definida como uma forma de expressar uma relação que o indivíduo vivenciou com o seu ambiente, sentida e experienciada na medida da sua motivação.

Sendo assim a Educação Física é capaz de conceber a experiência humana como instância reveladora do ser e do existir e o movimento humano como uma linguagem que sintetiza emoções e sentimentos. Mais que clínica, quartel escola, quadra, o corpo é mundo. (VARGAS, 1990, p. 61)

Quando se fala de seus aspectos emocionais, é necessário saber o que se entende por adolescentes. Segundo a Organização Mundial de Saúde (WHO, 2009), a adolescência é o período da vida, que começa aos 10 e vai até os 19 anos e segundo o Estatuto da Criança e do Adolescente (BRASIL, 2002), começa aos 12 e vai até os 18 anos, onde acontecem diversas mudanças físicas, psicológicas e comportamentais.

Nesse processo de mudanças (físicas e emocionais), o adolescente, na verdade, se vê totalmente confuso: até alguns meses atrás ele era uma criança em suas brincadeiras, atitudes, responsabilidades. Para alguns adolescentes essas decepções e frustrações tornam-se dolorosas demais e, na maioria das vezes, as famílias não sabem como lidar com este período de transição. Aberastury e Knobel (1981) explicam que isso acontece devido aos adolescentes estarem passando por um período de 'luto', pois seu corpo de criança já não existe mais. Além disso, as famílias também cumprem um período de luto pela perda dos corpos de crianças de seus filhos. Na busca da identidade, o adolescente recorre, como comportamento defensivo, à uniformidade, que pode proporcionar segurança e auto-estima pessoal. Aí surge o espírito de grupo, pelo qual o adolescente mostra-se tão inclinado. Há um processo de superidentificação em massa, onde todos se identificam com cada um. Por isso, inclina-se às regras do grupo em relação a modas, vestimentas, costumes, preferências de todos os tipos, etc. No grupo, o indivíduo adolescente encontra um reforço muito necessário para os aspectos mutáveis do ego que se produzem neste período da vida (ABERASTURY e KNOBEL, 1981).

As transformações físicas não são menos dolorosas do que as emocionais nos adolescentes. Nos meninos, a voz se modifica, surge acne, seu corpo na maioria das vezes parece que aumenta do dia para noite, sua locomoção parece ser mais difícil, caem com facilidade, tornam-se mais estabanados, pois precisam de um tempo para reeducar seus movimentos motores. Nas meninas, ao lado das dificuldades citadas, o crescimento dos seios é uma alteração visível que, além da alteração no centro de gravidade, provoca embaraço em algumas adolescentes, a ponto de usarem agasalhos grossos e quentes em aulas de Educação Física, independente do clima.

Devemos também estar alertas para a influência da mídia e dos valores econômicos sobre a Educação Física (CARVALHO, 2001). Alguns setores da Educação Física demonstram servir a interesses externos e alheios a ela, por exemplo, empresas de materiais esportivos, vestuário, academias, laboratórios de pesquisa e venda de suplementos alimentares, gerando verdadeiras fortunas, as quais, em nome de um padrão de saúde ou de um corpo de determinada forma e medidas, exploram crianças, adolescentes e adultos. Assim, se para os adultos, esta verdadeira 'fábrica' de informações padronizadas confunde e influencia, em consequência de uma sociedade consumista, quanto mais para os adolescentes, levando-se em consideração o processo de busca de identidade em que vivem, com tentativas de encaixar-se neste mundo que os atrai para valores superficiais e efêmeros.

As condições de vida em que os adolescentes estão inseridos podem determinar o grau de vulnerabilidade. Quanto maior a participação e o envolvimento familiar nas questões que dizem respeito ao adolescente, maior se torna sua confiança, melhorando sua auto-estima e, conseqüentemente, deixando-o mais protegido.

A contribuição da atividade física, nesta fase tão difícil para o adolescente, pode contribuir para o relaxamento, gasto de energia e percepção do próprio corpo e seu controle, além do convívio social com companheiros (VIEIRA, PRIORE, FISBERG, 2002).

Dessa forma, praticar atividades físicas pode aumentar a confiança e a auto-estima. A autoestima é um quesito importante para a vida satisfatória, funcionando como se fosse o sistema imunológico da consciência. Fornece resistência, força e capacidade de regeneração. A auto- 
estima saudável não é garantia de que uma pessoa nunca sentirá ansiedade e tristeza diante das dificuldades da vida, mas torna-a menos suscetível e mais equipada para suportá-las (CHIESA e CRUZ, 2002).

Assim, o presente projeto teve por objetivo criar subsídios para compreendermos qual a influência da atividade física no estado emocional de adolescentes, amenizando ou prevenindo características negativas de personalidade como agressividade, indiferença, individualismo, dificuldade de se relacionar com grupos diferentes, ansiedade e capacidade para aceitar as diferenças, seja nos aspectos sociais, raciais ou mesmo de habilidades durante as aulas de Educação Física.

\section{Participantes}

\section{Método}

Os participantes dessa pesquisa foram 100 alunos de $8^{\mathrm{a}}$ série de uma escola da rede SESI, da cidade de São Paulo, com idade entre 13 e 15 anos, meninos e meninas, após a autorização dos pais ou responsáveis e da direção da instituição. A pesquisa não ofereceu risco aos participantes, o sigilo quanto à identidade foi mantido e os participantes poderiam retirar-se da pesquisa a qualquer momento, se o desejassem. O projeto foi aprovado pelo Comitê de Ética em Pesquisa da Universidade Presbiteriana Mackenzie (14/03/2003)

\section{Instrumento}

Foi utilizado um questionário, com 27 perguntas diretas e objetivas (Anexo I), referentes às expectativas dos alunos em relação às aulas de Educação Física, às suas motivações em relação a essas aulas e possíveis alterações emocionais após estas aulas, assim como suas relações com o grupo de companheiros.

\section{Procedimento}

O questionário foi aplicado em grupo, durante as aulas de Educação Física, num período de 50 minutos.

Os resultados foram tabulados e apresentados em porcentagens para análise e discussão.

\section{Resultados e Discussão}

Quanto à pergunta 1 (Você gosta das aulas de Educação Física?), $97 \%$ dos participantes responderam positivamente, significando que, para a maioria, a Educação Física pode ser um espaço importante de convívio social, onde se mesclam as diferentes formas do pensar e do agir, onde as relações interpessoais se fazem necessárias para que esse convívio ocorra harmoniosamente.

Quanto à pergunta 2 (Você participa das aulas de Educação Física com entusiasmo?), 85\% dos alunos responderam positivamente, $4 \%$ responderam negativamente e para $11 \%$ é indiferente; ou seja, as aulas parecem ser um espaço motivacional para a maioria dos alunos. Por isso, na medida do possível, os planos de aulas deveriam ser elaborados com a participação dos alunos, para conhecermos também as expectativas dos alunos dentro das atividades a serem trabalhadas, já que, muitas vezes, não se pensa na especificidade dos grupos durante as aulas (MATTOS e NEIRA, 2000).

Em relação à pergunta 3 (Você participa das aulas de Educação Física por sentir-se obrigado, apenas para tirar notas, [exigência da escola?]), $3 \%$ dos alunos responderam positivamente, $93 \%$ responderam negativamente e $4 \%$ responderam que é indiferente. Ao observar esta questão, sua semelhança com as perguntas 1 e 3 foi intencional, para verificar a confirmação expressiva do resultado da importância dessa disciplina para esses alunos adolescentes. Como foi exposto anteriormente, a Educação Física pode ser uma aliada para se trabalhar com os adolescente, tanto do ponto de vista das relações sociais, como das dificuldades mais amplas que eles apresentam nesta fase da vida.

Considerando a questão 4 (Você sente-se incluído nas aulas de Educação Física?), 69\% responderam positivamente, $17 \%$ responderam negativamente e $14 \%$ de forma indiferente. Percebe-se que apesar de haver uma porcentagem significativa de respostas positivas, alguns grupos na classe têm grande dificuldade no ser incluído ou se incluir. Os alunos se incluem ou se excluem de acordo com as habilidades que acreditam possuir. Além disso, em determinados grupos, não são as habilidades que classificam determinados alunos e sim a grau de carisma, simpatia, beleza no caso de atividades mistas, interesses pessoais e até algum tipo de identificação grupal, como gosto por música, roupas e estilos, confirmando a influência de padrões impostos pela mídia (CARVALHO, 2001). 
Quanto à pergunta 5 (Seus pais praticam algum tipo de atividade física regularmente?), $29 \%$ responderam positivamente; $63 \%$ negativamente. Parece relevante a evidência de um alto índice de sedentarismo nesses pais. Tem-se a preocupação de usar os alunos como agentes multiplicadores, no que se diz respeito ao combate do sedentarismo familiar; porém os resultados ainda são tímidos. Além disso, quando se pensa na influência da família como fator de prevenção a riscos na adolescência, é maior ainda a necessidade de envolvimento dos pais nas atividades escolares, o que é confirmado pelas respostas à questão 6 (Seus pais incentivam-Ihe de alguma forma a participar das aulas de Educação Física ?), na qual $70 \%$ responderam positivamente e $16 \%$ responderam negativamente, sendo que para $14 \%$ foi indiferente. Embora não realizem atividades físicas regulares, os pais demonstram preocuparse com as atividades dos filhos e seu incentivo é fundamental para que estes se envolvam nas aulas de Educação Física.

Quanto à pergunta 7 (Você faz algum tipo de atividade física regularmente, sem ser nas aulas de Educação Física, como natação, futebol, voleibol ou outros?), $58 \%$ responderam positivamente e $\quad 39 \%$ responderam negativamente, sendo que para $3 \%$ a resposta foi indiferente. Estas respostas podem estar ligadas ao padrão sócio-econômico dos alunos, pois muitos deles relatam que, por contenção de despesas familiares precisaram parar as atividades físicas, confirmando a visão de Vieira, Priore e Fisberg (2002). Porém, elas demonstram também, que os adolescentes pesquisados só percebem como opção de atividades extras aquelas feitas em clubes e academias, desconsiderando a existência de muitas outras como caminhadas, andar de bicicleta, jogos nos condomínios, ruas ou parques, que independem de pagamento, podendo ser realizadas em espaços públicos.

Quanto à pergunta 8 (Você fica ansioso nos dias ou horas que antecedem às aulas de Educação Física?), $62 \%$ responderam positivamente e $19 \%$ responderam negativamente, sendo que para $19 \%$ foi indiferente. Considerando a porcentagem expressiva de respostas afirmativas a esta questão, percebe-se que a Educação Física parece influenciar os aspectos emocionais desses adolescentes, no sentido de expectativas em relação a quais atividades serão desenvolvidas durante as aulas.

Considerando a pergunta 9 (Você sente algum tipo de mudança no seu estado de humor após as aulas de Educação Física, tipo: feliz, triste, eufórico, outros?), $69 \%$ responderam positivamente, $17 \%$ responderam negativamente e para $14 \%$ foi indiferente. Sabe-se, no entanto, que essas alterações emocionais poderão ocorrer dependendo do grau de envolvimento desses alunos nas aulas e por características físicas individuais. Considerando as emoções como reações fisiológicas e psicológicas, que irão influenciar os aspectos cognitivos dos indivíduos (FIAMENGHI, 2001), está claro que as aulas de Educação Física poderiam ser momentos privilegiados para auxiliar os adolescentes a lidar com mudanças afetivas e sociais.

As respostas à questão 10 (Você e seus amigos costumam comentar sobre as aulas de Educação Física?), juntamente com as questões 11 (Você e seus amigos costumam comentar sobre as aulas de Educação Física que terão?) e 12 (Você e seus amigos costumam comentar sobre as aulas de Educação Física que tiveram?) confirmam a mesma idéia, de que um dos benefícios das aulas de Educação Física é o desenvolvimento de espaços para a sociabilidade. Aliás, este é um dos objetivos das aulas de Educação Física segundo os Parâmetros Curriculares Nacionais para a Educação Física (SECRETARIA DE EDUCAÇÃO FUNDAMENTAL, 1977). Na questão 10, 65\% responderam positivamente e $20 \%$ responderam negativamente, sendo que para $15 \%$ foi indiferente. Na questão $11,64 \%$ responderam positivamente, $24 \%$ responderam negativamente e, para, $12 \%$ a questão foi indiferente. $\mathrm{Na}$ questão $12,66 \%$ dos alunos adolescentes pesquisados responderam positivamente e $14 \%$ responderam negativamente, sendo que, para $20 \%$ a questão foi indiferente.

Quanto à pergunta 13 (Você prefere participar das aulas de Educação Física, quando você está triste ou com algum problema?), 53\% responderam positivamente, $24 \%$ responderam negativamente e para $23 \%$ a questão foi indiferente. As respostas levam-nos a refletir quanto à importância que a atividade física tem como ferramenta eficaz na diminuição do estresse na adolescência e na diminuição e 
prevenção de algum tipo de dificuldade emocional. Segundo Fiamenghi (2001, p.32) "estresse é o processo de ajustamento ou de lidar com circunstâncias que desorganizam ou ameaçam desorganizar o funcionamento físico ou psicológico de uma pessoa", e nesse processo, se for encontrada uma via adequada para a descarga da carga energética acumulada no organismo, o dano à saúde será reduzido (CHIESA e CRUZ, 2002). Além disso, as respostas à questão 14 (Quando você está triste e ou com problemas, a Educação Física, diminui sua tristeza ou the faz esquecer?) e 15 (Você prefere participar das aulas de Educação Física, quando você está feliz?) confirmam a importância da atividade física para os adolescentes como uma ferramenta eficiente, amenizando possíveis dificuldades emocionais que esses adolescentes possam estar sentindo, dificuldades essas de ordem física, social ou emocional, que não se tem como mensurar nesse estudo. Na questão 14 , $66 \%$ responderam positivamente, $18 \%$ responderam negativamente e para $16 \%$ a questão foi indiferente. Na questão 15, 69\% responderam positivamente, $5 \%$ responderam negativamente e para $26 \%$ a resposta foi indiferente. Deve-se lembrar, da importância de se ter espaços públicos onde adolescentes possam praticar atividades físicas com segurança e monitoramento de pessoas qualificadas para esse fim, como observado por Vieira, Priore e Fisberg (2002). Quando os adolescentes se encontram no ócio, eles se tornam presas fáceis da violência (RIBOLLA e FIAMENGHI, 2007).

As respostas à questão 16 (Você se relaciona bem com seus amigos durante as aulas de Educação Física?) demonstram que existem muitas influências dos grupos no relacionar-se, como exposto anteriormente, pois como os adolescentes estão formando sua identidade, eles se aproximam daqueles que lhes servem como referência, estabelecendo assim mais vínculos de amizade com determinados grupos cujos interesses são comuns (ABERASTURY e KNOBEL, 1981). Assim, para 65\% dos alunos pesquisados, as respostas demonstram que os adolescentes pertencem ao mesmo grupo ou têm os mesmos interesses em comum. Verifica-se também que $23 \%$ de alunos adolescentes pesquisados se mostraram indiferentes e $12 \%$ não se relacionam bem com os outros, levando à reflexão de que os professores devem empenharse no sentido de amenizar essa indiferença, para que os adolescentes possam aceitar e respeitar melhor as diferenças existentes dentro do grupo.

As respostas às perguntas 17, (Você lida bem com suas limitações ou seja, dificuldades que possa surgir durante um jogo [atividades] nas aulas de Educação Física) e 18 (Você aceita bem as limitações de seus amigos durante o jogo [atividades] nas aulas de Educação Física?), demonstram que os adolescentes pesquisados lidam bem com suas limitações e dificuldades, pois na questão $17,83 \%$ responderam positivamente e $12 \%$ responderam negativamente, sendo que $5 \%$ dos alunos pesquisados se mostraram indiferentes; já na questão $18,63 \%$ responderam positivamente, $13 \%$ responderam negativamente e, para $24 \%$ dos alunos, a resposta foi indiferente Além disso, as respostas demonstram a importância das atividades lúdicas durante as aulas de Educação Física, o que justificaria a falta de preocupação desses adolescentes em relação ao erro, seus e dos outros. As aulas de Educação Física devem propiciar aos alunos momentos agradáveis, onde as relações pessoais devem priorizar o respeito mútuo e que esse seja incentivado e firmado entre os grupos (VIEIRA, PRIORE e FISBERG, 2002).

Quanto à pergunta 19 (Você incentiva seus amigos durante os jogos [atividades] de Educação Física?), 69\% dos alunos responderam positivamente, $14 \%$ responderam negativamente e, para $17 \%$ a resposta foi indiferente. Os resultados podem indicar a preocupação com os amigos, significando que, para esses alunos, a amizade é mais significativa do que a vitória durante o jogo.

As questões 20 (Você precisa faltar na escola e tem a opção de escolher o dia dessa falta, você escolhe o dia em que não há aulas de Educação Física?), 21 (Você precisa faltar na escola e tem aula de Educação Física neste dia, você fica triste ou chateado por isso?) e 22 (Você esta na escola e por algum motivo, não pode fazer aulas de Educação Física, seja por motivo de saúde, ou outro qualquer. Você fica triste ou chateado?) mostram que a Educação Física pode ser uma ferramenta importante para minimizar a ausência (evasão) escolar desses alunos, pois mais da metade dos alunos escolheriam faltar às aulas em dias onde não houvesse aulas de Educação Física, sendo que $60 \%$ deles preferem não deixar de fazer as aulas de Educação Física. 
Quanto à pergunta 23 (Quando você vê modelos ou atrizes [atores] na mídia 'sarados' ou 'malhados', você se sente mais motivado a participar das aulas de Educação Física?), 33\% responderam positivamente, $36 \%$ responderam negativamente, e $31 \%$ se mostraram indiferentes. Pelas respostas apresentadas poderia parecer que os adolescentes pesquisados não são motivados pelos padrões da mídia.

Porém, as respostas às questões 24 (Você está feliz com seu corpo ou gostaria que ele fosse como de determinada[o] artista ou amiga[o]?) e 25 (Você se dedicaria mais, ou melhor, nas aulas de Educação Física, se tivesse certeza que teria alteração em 'formas ou medidas' de seu corpo?) sugerem uma realidade diferente.

$\mathrm{Na}$ questão 24 , apesar de $53 \%$ dos alunos adolescentes pesquisados responderem que estão felizes com seus corpos, é relevante observar que $23 \%$ de adolescentes não estão felizes com seus corpos.

$\mathrm{Na}$ questão 25 , observa-se que $58 \%$ dos alunos responderam afirmativamente, isto é, apresentam insatisfação com seu corpo. A motivação do aluno em participar das aulas, por acreditar poder alterar sua forma corporal, é importante. No entanto, as transformações muitas vezes poderão acontecer de maneira imperceptível para esses adolescentes. Sendo assim, eles devem ser orientados em relação aos padrões de corpo e de beleza estabelecidos pela mídia, expondo aos nossos alunos adolescentes os prós e contras de se seguir padrões estabelecidos em outras culturas, além da exploração comercial do corpo, transformando o supérfluo em essencial (CARVALHO, 2001).

É importante que o professor de Educação Física e a família tenham a percepção dos problemas que esses alunos adolescentes estão vivendo, para que essa insatisfação com o próprio corpo não venha a se transformar em algum distúrbio. Por exemplo, Fiamenghi (2001), descreve distúrbios da alimentação, como a anorexia e a bulimia, que apresentam relação com as expectativas sociais em relação ao corpo e estão aumentando entre os adolescentes. Percebe-se, portanto, que a mídia exerce influência sobre eles e que, de alguma forma, ela dita e estabelece padrões de beleza e de comportamento (STRASBURGER,1999).
Quanto à pergunta 26 (Quando você está jogando nas aulas de Educação Física, você sente vontade de vencer de 'qualquer jeito'?), $32 \%$ dos alunos responderam positivamente, $48 \%$ responderam negativamente e para $20 \%$, a resposta foi indiferente. Observa-se nessa questão a dificuldade de se trabalhar com jogos de competição nas aulas de Educação Física, por muitos alunos acreditarem que o mais importante dentro de uma competição (jogo) é a vitória. Talvez este seja um fator cultural, pois sabemos que em nosso país, para uma maioria de torcedores, só é considerada uma boa campanha numa competição, se a equipe ganhar o $1^{\circ}$ lugar. Outro fator importante que poderá nos auxiliar na reflexão dessa questão é comparar com a pergunta 7 , na qual $58 \%$ dos alunos fazem algum tipo de atividade física sem ser nas aulas de Educação Física, como por exemplo em clubes e escolinhas de esportes. Alguns desses estabelecimentos pregam a filosofia do vencer a qualquer preço, o que pode influenciar o pensamento e a motivação dos jovens em relação ao jogo (MATTOS e NEIRA, 2000).

Curiosamente, na pergunta 27 (Você gosta apenas de jogar, a vitória não é o mais importante?), $57 \%$ dos alunos pesquisados responderam positivamente, $17 \%$ responderam negativamente e, para $26 \%$, a resposta foi indiferente. Existe uma incompatibilidade nas respostas desta questão em relação à questão anterior, demonstrando que, ao contrário do resultado anterior, a maioria desses alunos se preocupa em participar dos jogos como sendo uma recreação, uma atividade lúdica demonstrando nessa questão o mais importante não é a vitória. Não se pode esquecer, portanto, a contradição como condição inerente ao próprio estado emocional de alguns adolescentes.

\section{Considerações Finais}

Ainda hoje existem muitos profissionais que priorizam ou privilegiam uma Educação Física seletiva, na qual apenas alunos com mais aptidão têm um lugar de destaque, afastando aqueles com menos habilidade.

Todos os alunos pesquisados responderam gostar das aulas de Educação Física; pode-se, portanto inferir, que a dificuldade de se relacionar ou de participar nas aulas ocorre por situações externas, por exemplo, o grupo social, ou os tipos de atividades ministradas nessas aulas. Daí a importância de se conhecer as expectativas 
desses alunos adolescentes em relação às aulas e havendo a possibilidade, o plano de aulas poderia ser pensado em conjunto com os alunos.

Em relação aos estados emocionais, as respostas também permitem concluir que os adolescentes percebem tanto a existência de emoções, como a alteração delas em decorrência da atividade física. Assim, as aulas de Educação Física podem ser espaços privilegiados para a compreensão das mudanças emocionais e de alternativas para que os adolescentes possam lidar positiva e construtivamente com estas emoções.

A importância da Educação Física sob o foco da sociabilidade e o respeito às diferenças entre os grupos também ficou evidenciada nas respostas às questões. Devido à importância das atividades lúdicas durante as aulas e havendo jogos estruturados, sugere-se que os professores estejam atentos às implicações negativas que poderão surgir com a competição, como o desrespeito às diferenças, sejam elas quais forem e o cuidado com idéia de 'vencer a qualquer custo'.

Portanto, o profissional de Educação Física deve, ele mesmo, procurar desenvolver o respeito às diferenças e um padrão ético e moral elevado em seu comportamento, além de perceber que o modelo imposto por grupos sociais, principalmente veiculados pela mídia, deverá ser cuidadosamente evitado quando se trata de lidar com adolescentes.

O valor da Educação Física como disciplina que educa para a sensibilidade, a importância e o respeito ao próprio corpo e ao dos outros deve ser preservado, a despeito das imposições efêmeras de uma realidade social distorcida; os adolescentes são presas fáceis dessas armadilhas, mas também podem ser valiosos instrumentos de mudança para uma nova maneira de enxergar-se e ao outro.

\section{Referências}

ABERASTURY, A.; KNOBEL, M. Adolescência normal. Porto Alegre: Artes Médicas, 1981.

BRASIL. Estatuto da Criança e do Adolescente (ECA). 12ª . Edição. São Paulo: Saraiva, 2002.

CARVALHO, Y.M. O "mito" da atividade física e saúde. São Paulo: Hucitec, 2001.

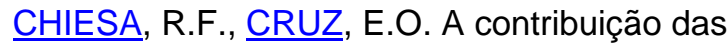
atividades físicas e artísticas na relação adolescência e família. Psicologia: Teoria e Prática, 4, 2002.
FIAMENGHI, G.A.. Motivos \& emoções . São Paulo: Mennon, 2001.

MATTOS, M.G.; NEIRA, M.G. 2000 . Educação

física na adolescência: construindo o conhecimento na escola. São Paulo: Phorte Editora.

RIBOLLA, M. B. e FIAMENGHI, G. A..

Adolescentes na escola: Representações sociais sobre violência. Psicologia Escolar e

Educacional, 11(1), 111-121, 2007.

SECRETARIA DE EDUCAÇÃO FUNDAMENTAL. Parâmetros curriculares nacionais - Educação Física. Brasília: MEC/SEF, 1977

STRASBURGER, V.C. Os adolescentes e a mídia: impacto psicológico. Porto Alegre: Artmed, 1999.

VARGAS, A.L.S . Educação física e o corpo: a busca de identidade. Rio de Janeiro: Sprint, 1990

VIEIRA, V.C.R., PRIORE, S.E.; FISBERG, M. A atividade física na adolescência. Adolescência Latinoamericana, v.3, n.1, 2002.

WHO (World Health Organization). Adolescence health. Disponível online:

http://www.who.int/topics/adolescent health/en/. Consultado em 05/05/2009.

Endereço:

Geraldo Antônio Fiamenghi Jr / Elio Oliveira Cruz Universidade Presbiteriana Mackenzie - CCBS Pós-Graduação em Distúrbios do Desenvolvimento

R. da Consolação, 896, Prédio 16, sala 03 São Paulo SP Brasil 01302-920

Telefone: (11) 2114.8247 e (11) 2114.8707 e-mail: geraldo.fiamenghi@mackenzie.br elio.oc@globo.com

Recebido em: 08 de maio de 2009.

Aceito em: 05 de março de 2010.

Motriz. Revista de Educação Física. UNESP, Rio Claro, SP, Brasil - elSSN: 1980-6574 - está licenciada sob Licenca Creative Commons 